\title{
DIGITAL (4) EDUCATION - A NATIONAL DIGITAL STRATEGY IN THE CONTEXT OF THE TRANSFORMATION OF A COUNTRY INTO A DIGITAL NATION
}

Serge Linckels, Ministry of Education, Luxembourg

\section{Introduction}

This paper describes Luxembourg's strategy "Digital (4) Education" by the Ministry of Education, Children and Youth to leverage learning to the $21^{\text {st }}$ century. It is divided into three areas: media literacy, educational technologies, and promotion of STEM. The strategy is embedded into the overarching national strategy "Digital Luxembourg" which is the governmental programme to transform the country into an IT nation.

\section{Disclaimer}

The following text is for general information purposes only. Although the author was professionally implied in the creation of the Digital (4) Education strategy, this paper presents the author's personal and subjective view and interpretation and does not reflect the ministries position or intentions.

\section{General governmental context}

\section{Governmental programme}

On 10 December 2013, Luxembourg's Prime Minister Xavier Bettel presented the governmental programme to the national parliament. This programme recommends, at a policy level and among other things, using more modern teaching material and in particular influencing the quality of daily work.

"To ensure more individual care of the student in teaching, emphasis should be placed on factors that directly influence the quality of classroom work. The aim will be to ensure better teacher training, more modern teaching material and a contribution to new didactic ideas in the daily work of teachers."

In November 2018, a new Ministry of Digitalisation was created, whose mission

"is to sustain the general technological development in the areas important to Luxembourg's economy and to develop new strategies for Luxembourg to move forward, but also to improve the daily lives and the various administrative processes. Much of the work of the ministry is focused on making people's lives easier." 
In January 2019, the Prime Minister announced a national strategy on artificial intelligence and stated that if Luxembourg wants to continue positioning itself in the digital world, artificial intelligence appears as a new pillar to build.

"We will federate the ecosystem of skills, for example by supporting courses in the field, from an up skilling perspective, but also research. And we will showcase those who are already champions in artificial intelligence, to attract those who need these skills."

\section{Digital Luxembourg}

On 20 October 2014, Prime Minister and minister of Communications and Media, Xavier Bettel, presented "Digital Luxembourg" as an initiative, which aims to strengthen and consolidate Luxembourg's position in the field of information and communication technologies (ICT) and to make the Grand Duchy a real centre of high-tech excellence. It focuses on the six topics: infrastructure, eSkills, innovation, FinTech, e-Administration, and promotion (see Figure 1).

As part of the strategy, Luxembourg's schools must train young people who will be able to adapt to the acceleration of change, i.e. who will be characterised by their openness to innovation and their ability to take advantage of the uncertainty generated by an unknown future. Digital technologies can also be an important factor in reducing inequalities. On the one hand, it provides all students, regardless of their social background, with access to quality cultural and educational information and resources. On the other hand, digital technologies make it possible to diversify learning methods and to better adapt teaching to the needs and pace of each individual.

Within the eSkills theme, education has developed its Digital (4) Education strategy. 


\section{Digital Luxembourg}

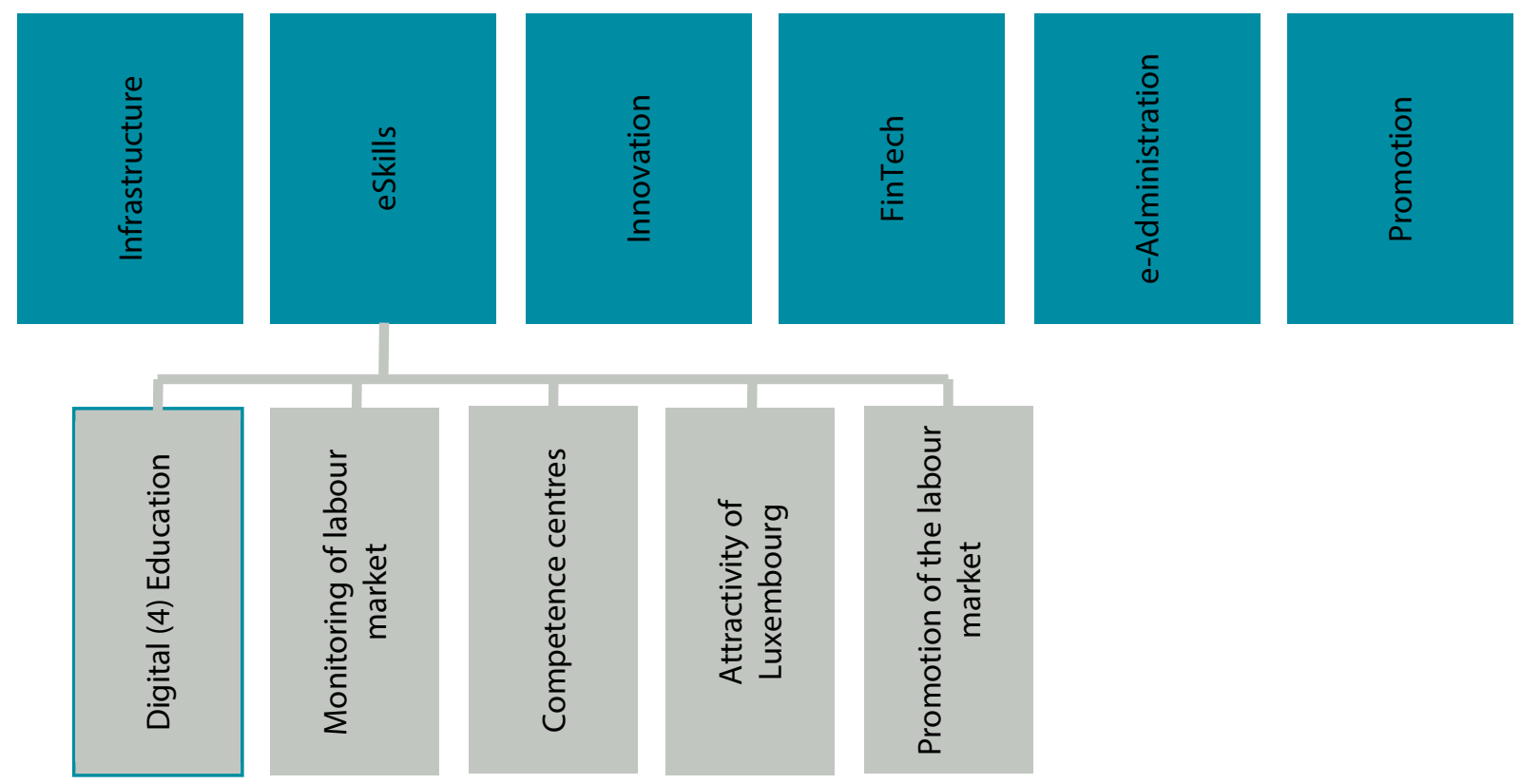

Figure 1. Themes of the national strategy "Digital Luxembourg"

\section{Digital (4) Education}

On May 20 2015, Claude Meisch, Minister of Education, Children and Youth, presented the strategy "Digital (4) Education". The name of the strategy allows for a double reading that perfectly illustrates the two priority objectives:

- Digital education: the preparation of young people for a complex and constantly changing working environment and their role as citizens in the private and public sector.

- Digital for education: the promotion of new learning strategies and innovative pedagogical projects, using digital technology in schools and in the extracurricular world.

The Digital (4) Education strategy is structured around the following five dimensions:

- Digital citizen: The school will introduce students to key computer applications that are essential in their future lives as citizens, such as: administrative procedures, communication with the authorities, and e-banking.

- Digital peer: Young people will learn to use ICT in a more secure and responsible way. In particular, Internet safety, moral harassment in social media, and image rights will be discussed.

- Digital learner: To create learning situations that foster the development of $21^{\text {st }}$ century skills, a learning and teaching environment with appropriate resources will be made available to teachers and students. 
- Digital worker: Students will be encouraged to develop the skills necessary to handle basic technological tools in their future professional life.

- Digital entrepreneur: Activities are being implemented to stimulate talent, encourage young people to take an interest in technological tools and thus contribute to the training of future specialists in the digital economy.

\section{Digital (4) Education's three focus areas}

The Digital (4) Education strategy is based on five dimensions presented in the previous section that are broken down into specific projects. These precise actions are grouped in three areas: media literacy, educational technology, and promotion of STEM (see Figure 2). Each project provides school or extracurricular actors with the necessary tools (software, hardware, pedagogical resources, pedagogical scenarios, learning places...) to create learning situations that promote the development of skills for the $21^{\text {st }}$ century.

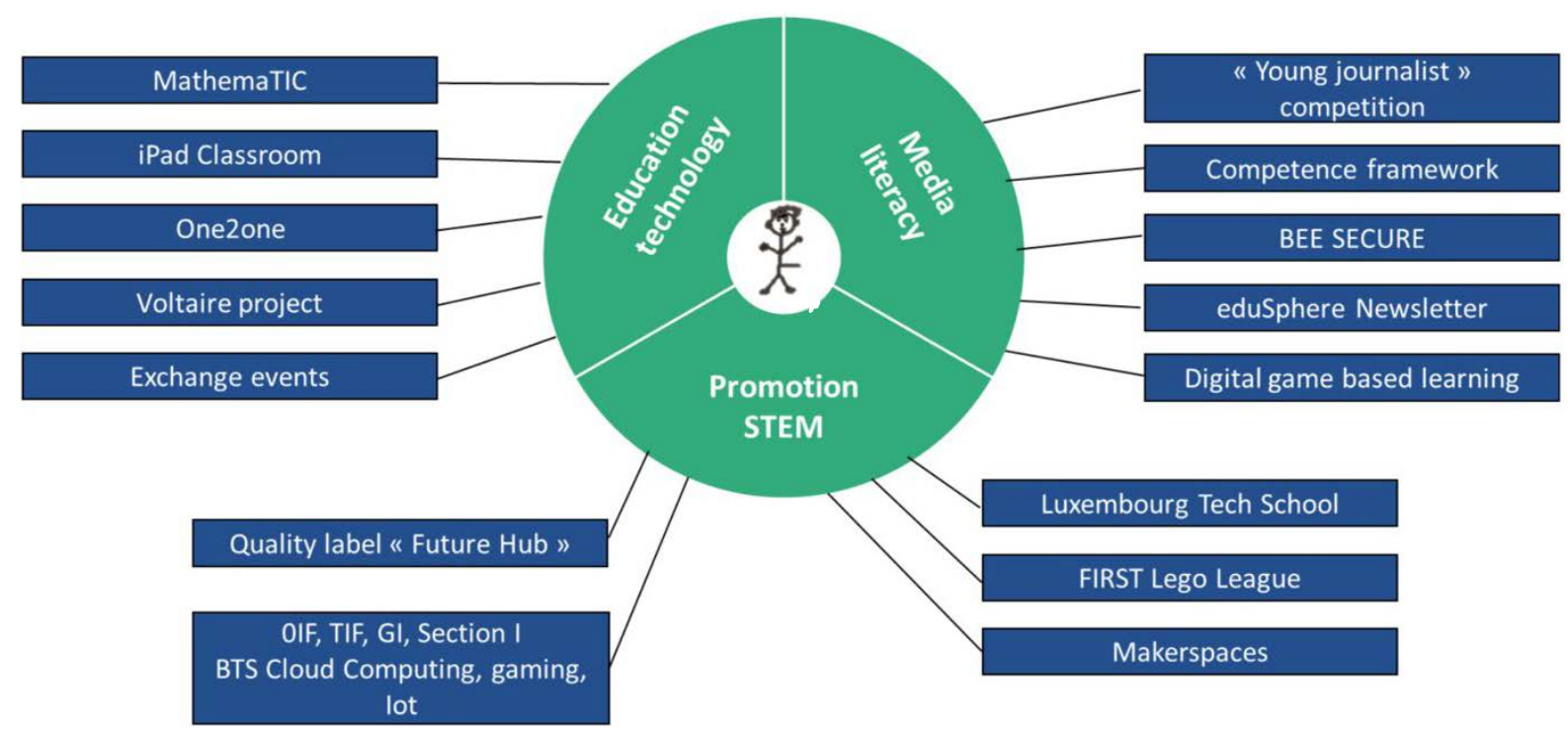

Figure 2. Areas of activities of the strategy "Digital (4) Education"

\section{Area 1: Media Literacy}

The objective is to prepare young citizens to become members of a modern and highly technical society with all its opportunities, challenges and dangers. Today's children are natives of the digital age. However, the challenges of education and the extracurricular world related to technological tools remain enormous. How can we prevent young people from becoming passive consumers switching from one medium to another, without being able to appropriate the information? How to develop the knowledge, skills, and attitudes they will need to find jobs in emerging or evolving sectors?

Education has the obligation to equip young people with the skills and knowledge they will need to adapt in our changing world. These skills are two-folded: 
1. To prepare young people to live in a complex and constantly changing work environment. Therefore, education must develop skills in four key areas: communication, collaboration, creativity, and critical thinking.

2. To prepare young people to assume their role in the private and public domain. Therefore, education must offer learning situations that foster understanding of the world and society, personal development, and well-being.

Precise actions have been put in place. Here is a non-exhaustive list:

- In collaboration with the national press council, the young journalist contest aims at explaining the process of news-creation, the importance of the quality of the source of information, the danger of fake news, etc. to the students. Journalists visit primary and secondary schools and help the students produce a journalistic work. The best submissions are presented in a traveling exhibition.

- "BEE SECURE" is a programme to inform students, parents, and teachers in a simple language about the dangers on the Internet. Workshops are organised, pedagogical material is made available in different languages, and experts visit schools. Every year, a campaign is launched with a specific topic, e.g. Love stories (2018-2019) and Big data (2017-2018).

- In compliance with the European model "DigComp", a national digital competencies framework is under development that apply for all grades (primary and secondary). Among the 16 competencies grouped into five areas (see Figure 3), lesson plans, best practices, teacher trainings, events, etc. will be part of the whole package.

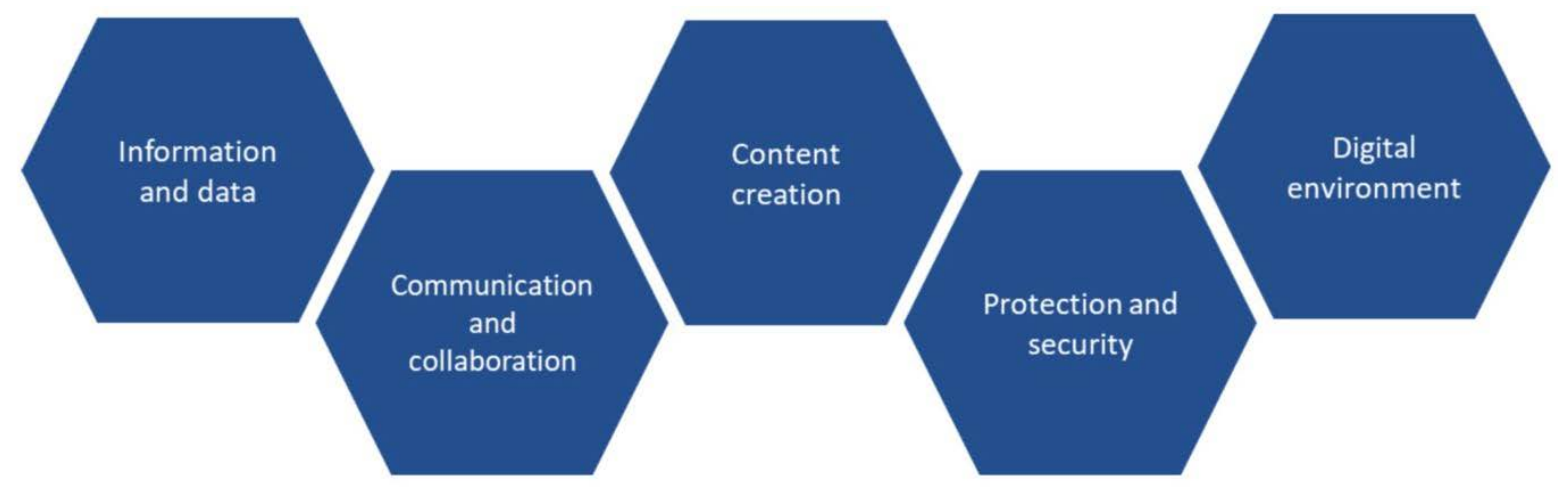

Figure 3. Five areas of the European digital competencies framework (DigComp)

- In its efforts to inform all teachers about new trends, events, challenges, trainings, etc. the Ministry of Education publishes every month the "eduSphere newsletter" and organises as a key event called "eduSphere day", which is a whole day of practical training for teachers. The workshops present inspiring practices and allow teachers to exchange their experiences. The topics range from 3D printing, laser cutting, robotics, green screen towards the use of specific apps and tablets in class.

- To learn about the potential of digital game based learning in education, experiments were made in different schools (primary and secondary) in cooperation with the University of Luxembourg and the Donau University in Krems (Austria). First 
promising results were presented in January 2019 at a meeting of the European Commission's DG EAC working group on digital education. Additionally, the creation of national and international networks as well as the elaboration of appropriate learning resources, i.e. games, are all initiatives that allow the strategic development and implementation of this pedagogical approach.

\section{Area 2: Educational technology}

The objective of the activities in this area are to support learning with digital tools (hardware and software) which shall foster a more student centred and practical learning. The following incomplete list illustrates some of the actions put in place.

- "MathemaTIC" is a personalised learning environment for mathematics. It allows students to learn in an individual way at their pace by using interactive learning activities. All exercises are consistent with the curriculum and its objectives. Due to Luxembourg's multi-linguistic population, the content is available in four languages: German, French, Portuguese and English. The particularity of MathemaTIC is that students are provided with learning activities that best fit their current level of knowledge. The system provides teachers with a constant overview of their students' performance.

- The programme "one2one" was initiated to reduce inequalities and to allow every student, independently of their social background, access to digital learning resources. Tablets are deployed under a leasing contract to ensure that all students will be able to own such a device. In pair with the one2one program, new learning scenarios and digital resources are made available to profit as much as possible of the added values of the tablets.

- As teachers are the key component of the success of any educational approach, their continuous professional development is essential. The national training institute for teachers (IFEN) offers a large variety of courses in the domain of media literacy and educational technology, as well as on other connected topics like GDPR, author rights and deontology on social networks. Such courses were also integrated into the initial teacher training (primary and secondary).

- The Ministry of Education is in the process of updating existing curricula in order to adapt them to the digitalisation of daily life. For the sake of illustration, the classical "Technician in electrical engineering" is transformed into "Technician in smart technologies" to prepare the students to technologies on industry 4.0, smart home, renewable energy and electric mobility. New curricula are created, e.g., in eCommerce and computer sciences.

\section{Area 3: Promotion of STEM}

According to Cedefop (European skills and jobs survey, 2018), 43\% of adult employees in the European Union have recently been affected by digitisation in their jobs, e.g. by the introduction of a new ICT tool or processes to automate tasks. More specifically, the study suggests that $14 \%$ to $18 \%$ of jobs are at risk and that future employees will need to have the 


\section{Digital (4) Education - A National Digital Strategy in the Context of the Transformation of a Country into a Digital Nation \\ Serge Linckels}

know-how required by this new way of working in a digital world. This risk is greater for routine jobs and is likely to affect mainly lower-skilled workers. However, other positions in the tertiary sector are also concerned and traditional tasks such as document management are impacted by digitisation.

A Eurofund study (Overview of new forms of employment, 2018) found that it is not only a question of job substitution, but that digitisation also implies that new tasks must be considered in old jobs. As a result, continuous professional development is more necessary than ever to acquire digital skills such as coding.

According to the European Commission (Digital Skills \& Jobs, 2019), up to 500.000 ICT jobs will remain vacant in Europe by 2020. However, the number of graduates leaving education does not meet that demand.

Luxembourg is lacking not only of (highly) qualified experts, but also youngsters that are interested in ICT studies or trainings. Therefore, the aim of this third area of Digital (4) Education is to modernise the offer of curricula and to attract more students to this sector of the labour market. The 2018-2023 coalition agreement of the Luxembourg government sets the political priority to equipping students with the skills that are required by the digitalisation of the labour market. Some specific initiatives are listed here as illustration.

- The Ministry of Education created the label "Future Hub" to promote secondary schools that are open to technology and innovative learning from science, technology, engineering, and mathematics (STEM). The Future Hub schools integrate a variety of training and specialisation courses with technological characteristics in their school offer. The integration of technologies in learning methods while promoting students' creativity and sense of initiative is fostered.

- New ICT curricula were created at different levels of the school system, from lower secondary, over VET, towards higher secondary. These offers have a strong focus on computer sciences and communication, and allow graduates access to university studies in the related field.

- Following a strong demand from industry on highly qualified and immediately operational work force, a two year curricula of higher education was extended to computer science topics. This "Brevet de Technicien Supérieur" (BTS) is offered in different secondary schools according to their local speciality and orientation, e.g. Internet of Things (IoT), Game Art \& Game Design, Game Programming \& Game Design, and Cloud Computing. Collaboration with external actors in these fields allows developing and adapting a leading-edge school offer.

- The "Luxembourg Tech School" is a new extracurricular programme that supports the development of future digital leaders. It is aimed at 15-19 year-old learners who are passionate about the digital environment and eager to learn about the use and application of technology in a real business context. The activities cover different topics, e.g. game development, big data, FinTech, and space. 
- "BEE CREATIVE" is a project which aims to motivate students to create using technical tools and to promote entrepreneurship. The project culminated in 2015 in the launch of several educational makerspaces. A makerspace is a place where young people can discover and create. It is also an opportunity to meet other young people and embark on maker-projects together. Such sessions are always free of charge and are accompanied by experts in the field. Learners can accomplish projects such as: build their own drone or robot, develop their own video game, or create their own music.

\section{Conclusion}

Digital (4) Education is an ongoing strategy by Luxembourg's Ministry of Education, Children and Youth and is constantly extending its broad variety of activities in formal, nonformal and in-formal education according to its key objectives.

\section{References}

Cedefop (2018). European skills and jobs (ESJ) survey. Retrieved March 10, 2019, from http://www.cedefop.europa.eu/en/events-and-projects/projects/european-skills-and-jobsesj-survey

Eurfound (2018). Overview of new forms of employment. Retrieved March 10, 2019, from https://www.eurofound.europa.eu/sites/default/files/ef_publication/field_ef_document/ef 18050en.pdf

European Commission (2019). Digital Skills \& Jobs. Retrieved March 10, 2019, from https://ec.europa.eu/digital-single-market/en/policies/digital-skills 